\title{
Common biomarkers of oxidative stress do not reflect cardiovascular dys/function in rats
}

\author{
Premysl Mladenkaa, Libuse Zatloukalovaa, ${ }^{a}$ Tomas Filipsky ${ }^{a}$, Jaroslava Vavrova ${ }^{b}$, Magdalena Holeckova ${ }^{b}$, Vladimir Palicka ${ }^{b}$, \\ Radomir Hrdina ${ }^{a}$
}

Background. Predicting cardiovascular events remains challenging despite the range of known biomarkers. Aim. To establish relationships between various biochemical and functional parameters of the cardiovascular system. Method. The relationship between cardiovascular dys/function and various biomarkers was examined in 145 experimental rats half of which received isoprenaline $100 \mathrm{mg} / \mathrm{kg}$ s.c. to induce cardiac impairment.

Results. Serum concentration of cardiac troponin T (cTnT), a known marker of cardiac derangement, correlated strongly with degree of myocardial injury (e.g. calcium overload, stroke volume) but correlations between cTnT and oxidative stress parameters were weak (for glutathione and vitamin $\mathrm{C}$ ) or not found (for serum vitamin $\mathrm{E}$ and plasma thiobarbituric acid reactive substances levels). Relationships between cTnT and other parameters were exponential with the exception of myocardial calcium, where a power function was found.

Conclusions. Commonly used biomarkers of oxidative stress cannot reliably predict cardiovascular dys/function in experimental rats.

Keywords: oxidative stress, cardiovascular disease, catecholamines, acute myocardial infarction

Received: November 1, 2012; Accepted with revision: April 25, 2013; Available online: May 28, 2013

http://dx.doi.org/10.5507/bp.2013.033

${ }^{a}$ Department of Pharmacology and Toxicology, Faculty of Pharmacy in Hradec Kralove, Charles University in Prague, Hradec Kralove, Czech Republic

bInstitute for Clinical Biochemistry and Diagnostics, Faculty of Medicine in Hradec Kralove, Charles University in Prague and University Hospital Hradec Kralove, Hradec Kralove

Corresponding author: Premysl Mladenka, e-mail:mladenkap@faf.cuni.cz

\section{INTRODUCTION}

Cardiovascular diseases are a leading cause of mortality and morbidity worldwide, accounting for around 17 million of deaths each year. Although recent trends in health care have slightly reduced fatal cardiovascular events, the incidence cardiovascular disorders is not decreasing. Moreover, the high prevalence of these diseases is no longer the prerogative of developed nations. Risk factors for cardiovascular diseases are well known, but predicting a cardiovascular event remains challenging, despite the number of known biochemical markers ${ }^{1-4}$. Involvement of oxidative stress in some cardiovascular diseases is clearly suggested in most studies, although the relationship of oxidative stress markers and cardiovascular mortality is equivocal and clinical use of antioxidants is inconclusive ${ }^{5,6}$.

Coronary heart disease accounts for more than 40\% of cardiovascular deaths and its most serious form, acute myocardial infarction (AMI), is the principal cause of chronic heart failure ${ }^{1}$. Elevated catecholamines are known risk factors for a cardiovascular event and the synthetic catecholamine, isoprenaline has been used for about a half a century for inducing AMI and subsequent heart failure in small laboratory animals ${ }^{7-10}$. In our previous study, we found in a very small number of animals some correlations among various parameters in healthy and AMI- induced animals ${ }^{10}$. The study reported here was aimed at a more detailed analysis: 1) to confirm the association of the cardiovascular injury and its known biochemical markers; 2) to analyze the relationship of common biomarkers of oxidative stress and degree of cardiovascular dys/function. The animals were intentionally not stratified to mimic normal population with the presence or absence of cardiovascular disorders, as well as treated and untreated patients. Moreover, the use of animals in this study enabled analysis of myocardial elements, in particular calcium and this cannot be performed in humans.

\section{METHODS}

\section{Animals and measurements}

Our group recently analysed the effects of different drugs with iron chelating properties on the isoprenaline model of cardiac toxicity in rats. Most of the data have already been published as studies of the effects of iron chelating drugs on this mode ${ }^{10-14}$. The present study was an analysis of the data from a total of 145 young male Wistar: Han rats (Biotest s.r.o. Konárovice, Czech Republic) from another viewpoint. All experiments conformed to "The Guide for the Care and Use of Laboratory Animals" published by the US National Institutes of Health (NIH Publication No. 85-23, revised 1996) and were performed 
with the approval of the Ethics Committee of Charles University in Prague, Faculty of Pharmacy in Hradec Králové.

The experimental procedure was the same in all animals. Detailed methodology can be found in our publications (e.g. ref. 10, 12, 13). In brief, all animals received i.v. various agents with iron chelating properties or solvent; 72 animals received $100 \mathrm{mg} / \mathrm{kg}$ isoprenaline (Sigma-Aldrich, USA) s.c. in a 5 min interval to induce myocardial impariment; 73 rats formed the controls. After $24 \mathrm{~h}$, the anaesthesized animals (urethane $1.2 \mathrm{~g} / \mathrm{kg}$ i.p.,
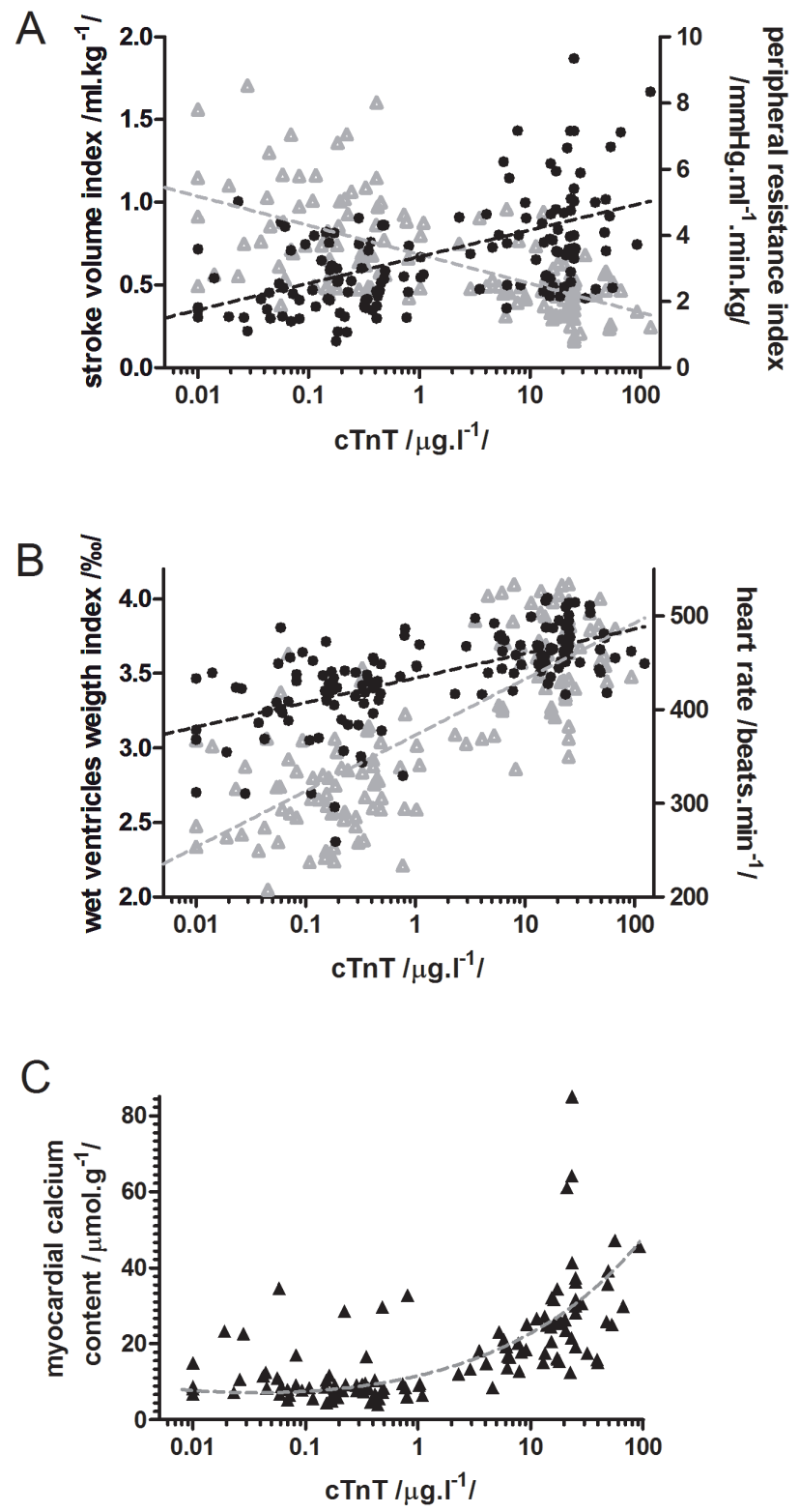

Fig. 1. Relationship of cardiac troponin $\mathrm{T}$ in serum with stroke volume, peripheral resistance index (A), wet ventricle weight index, heart rate (B) and myocardial calcium content (C).

Equations are as follows: the stroke volume index $=-0.17 \mathrm{log}$ $(\mathrm{cTnT})+0.68 / \mathrm{R}^{2}=0.37 /$; the peripheral resistance index $=0.76$ $\log (\mathrm{cTnT})+3.38 / \mathrm{R}^{2}=0.24 /$; the wet ventricle weight index $=$ $0.36 \log (\mathrm{cTnT})+3.09 / \mathrm{R}^{2}=0.55 /$; the heart rate $=25 \log (\mathrm{cTnT})$ $+434 / \mathrm{R}^{2}=0.39 /$; the myocardial calcium content $=1.45 \mathrm{cTnT}^{-0.25}$ $+10.25 \mathrm{cTnT}^{0.33} / \mathrm{R}^{2}=0.53 /$.
Sigma-Aldrich, USA) were connected to the instrument Cardiosys $^{\circledast}$ (Experimentria Ltd, Hungary) with software Cardiosys 1.1. for the measurement of haemodynamic variables. At the end of the experiment, blood was withdrawn and the heart excised for analysis of antioxidants, enzymes and metal ions in the myocardium. Cardiac troponin $\mathrm{T}$ (cTnT), vitamin $\mathrm{E}$, and vitamin $\mathrm{C}$ were measured in serum, thiobarbituric acid reactive substances (TBARS) in plasma, antioxidant enzymes SOD and GPx in erythrocytes and the total glutathione in the whole blood. Standard approaches were used for the analysis: SOD and GPx were determined by commercial kits (Randox, United Kingdom), cTnT by electroluminescence immunoassay (Roche Diagnostics, Germany), vitamin E by fluorimetric detection, the total blood glutathione and vitamin $\mathrm{C}$ by UV detection. Iron, copper, and selenium were determined using graphite furnace atomic absorption spectrometry. Zinc was determined using flame atomic absorption spectrometry and calcium was measured photometrically using flame photometry.
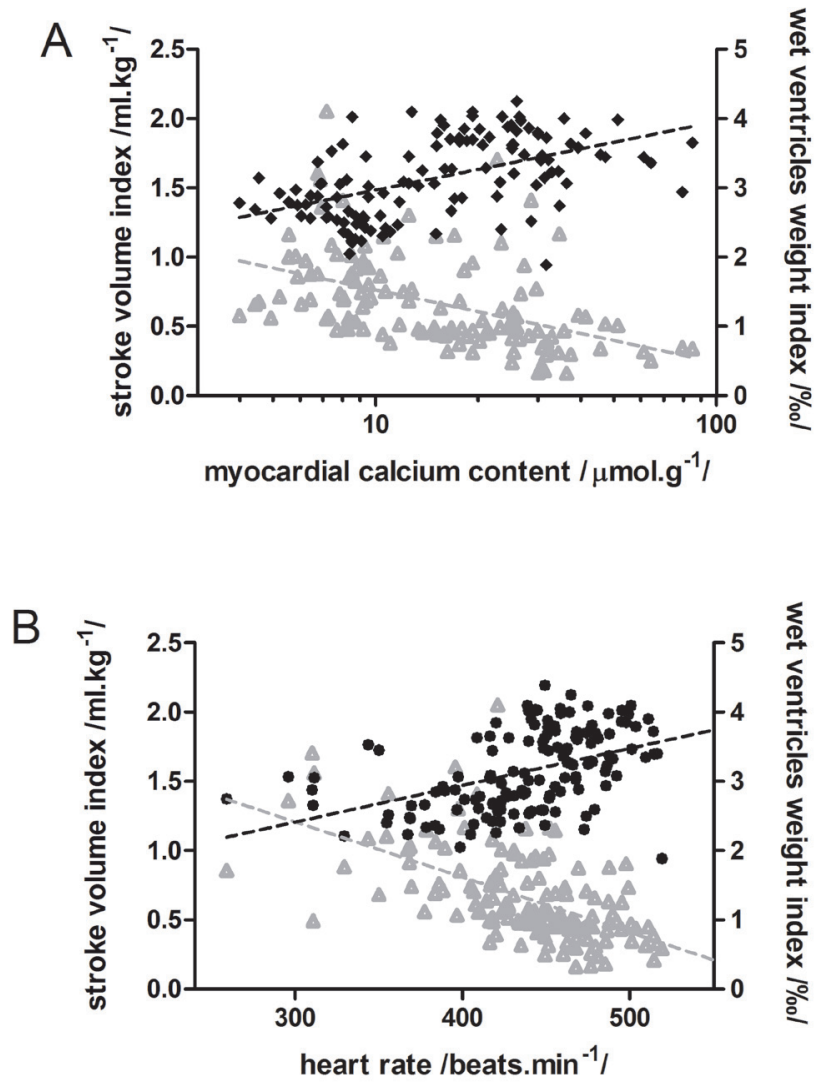

Fig. 2. Relationship of myocardial calcium content (A) and heart rate $(\mathrm{B})$ with the wet ventricle weight and stroke volume index.

Equations are as follows: the stroke volume index $=-0.52 \mathrm{log}$ (Ca) $+1.29 / \mathrm{R}^{2}=0.21 /$; the wet ventricle weight index $=0.99 \mathrm{log}$ (Ca) $+1.98 / \mathrm{R}^{2}=0.27 /$; the stroke volume index $=-0.004 \mathrm{x}$ heart rate $+2.404 / \mathrm{r}^{2}=0.34 /$; the wet ventricle weight index $=0.005 \mathrm{x}$ heart rate $+0.815 / \mathrm{r}^{2}=0.20 /$. 

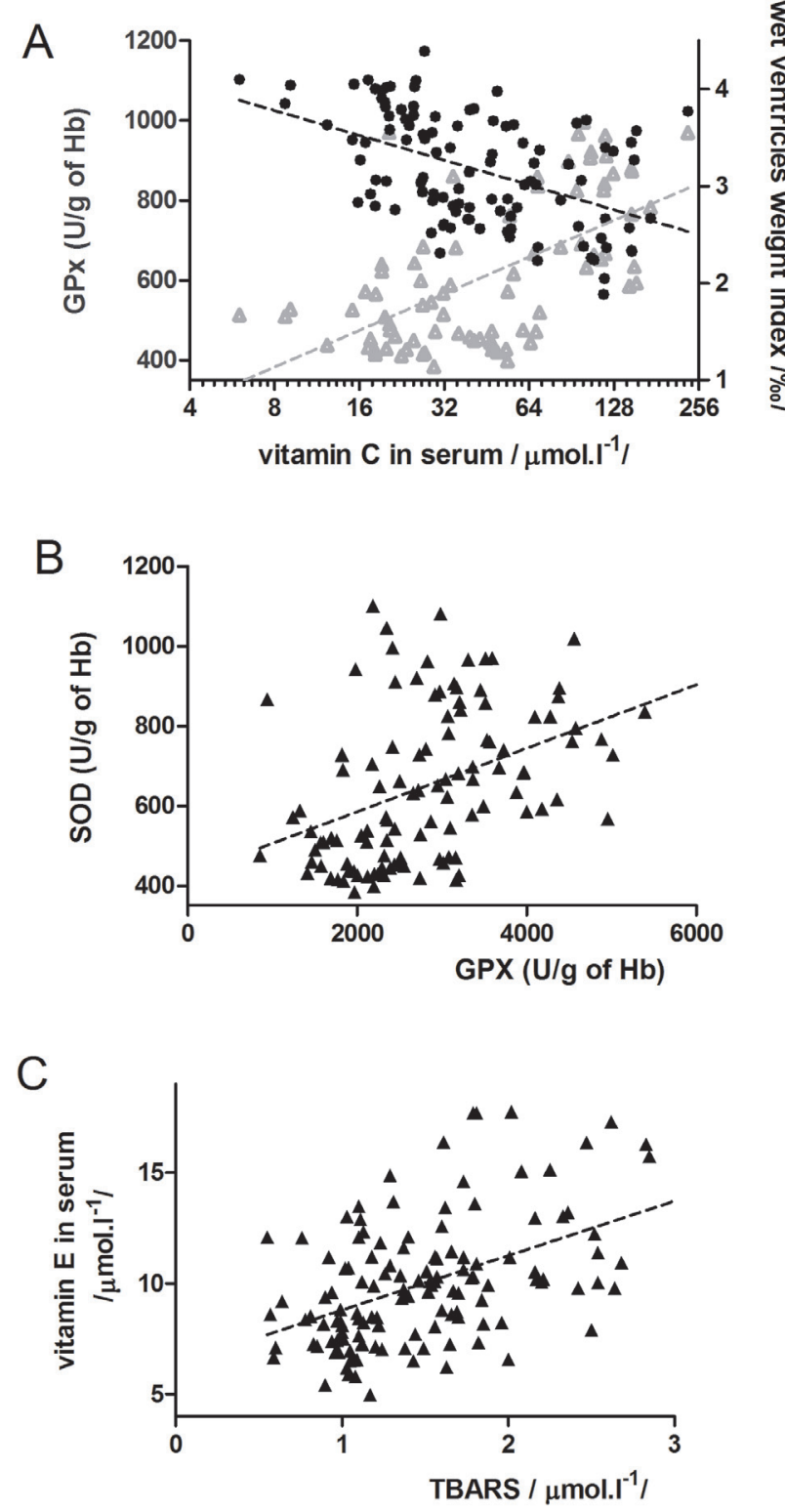

Fig. 3. Relationship of vitamin C serum concentration with the wet ventricle weight and GPx activity (A), of GPx and SOD activities (B) and between TBARS concentration and vitamin E serum level (C).

Equations are: $\mathrm{GPx}=305.3 \times \log ($ vitamin $\mathrm{C})+106.9 / \mathrm{R}^{2}=0.36 /$; wet ventricle weight index $=-0,85 \times \log ($ vitamin $C)+4.55$ $/ \mathrm{R}^{2}=0.23 / ; \mathrm{SOD}=0.080 \mathrm{GPx}+426.2 / \mathrm{r}^{2}=0.19 / ;$ vitamin $\mathrm{E}=2.46$ $\mathrm{x}$ TBARS $+6.35 / \mathrm{r}^{2}=0.23 /$

"Double product" was calculated as a product of the systolic blood pressure and heart rate and the total peripheral resistance was calculated as the mean arterial blood pressure divided by cardiac output. Stroke volume, wet ventricles weight and the total peripheral resistance are expressed as indices (variables divided by the body weight).

\section{Statistical analysis}

Each data set was firstly checked by D'AgostinoPerson normality test for Gaussian distribution. Data sets with non-Gaussian distribution were analysed by the use of non-parametric Spearman's correlation test and those with Gaussian distribution with Pearson's test. The minimal level of the statistical significance was $P \leq$ 0.05. Data with the correlation coefficient higher than 0.45 were analyzed by linear or non-linear regression. All data analyses were performed by the use of GraphPad Prism 5.0 for Windows (GraphPad Software, San Diego, California, USA).

\section{RESULTS}

The correlations were performed for all parameters with the exception of the derived parameters (e.g. double product and blood pressure). Significant correlation coefficients are shown in Table 1. The detailed relationship of the variables with correlation coefficients higher than 0.45 is depicted in Fig. 1-3.

There was a high correlation between levels of cTnT and total peripheral resistance, wet ventricle weight, myocardial calcium content, heart rate but only a weak correlation of cTnT with diastolic blood pressure and the "double product". Except for calcium concentration, the relationship was linear in the semilogarithmic plot. A more complicated relationship of the type of a power function was found between myocardial calcium level and serum cTnT. A negative strong association was found for cTnT and stroke volume, again with a linear character in the semilogarithmic plot. A weaker negative association with total blood glutathione and serum vitamin $\mathrm{C}$ concentrations was disclosed. No significant association was found for vitamin E, TBARS, SOD and other myocardial elements with cTnT.

The relationships of heart rate, myocardial calcium levels and wet ventricle weight with these parameters were very similar to those of cTnT (Table 1, Fig. 2 vs. Fig. 1).

The total peripheral resistance was likewise positively associated with cTnT, myocardial calcium, wet ventricle weight and heart rate and negatively with the total blood glutathione. But in addition to these parameters, a positive moderate correlation was found with TBARS.

Stroke volume index correlated positively with the total blood glutathione and weakly negatively with TBARS, GPx and myocardial zinc concentration in addition to the stronger correlations mentioned (cTnT, Ca, wet ventricle weight, heart rate). The total blood glutathione correlations were mostly less expressed, but the mentioned negative correlation with total peripheral resistance supports the previous results.

For serum antioxidants (vitamin $\mathrm{C}$ and vitamin $\mathrm{E}$ ), the correlations were rather opposite. Vitamin $\mathrm{C}$ correlated very negatively with wet ventricle weight and moderately with cTnT. Relatively high positive correlations of vitamin $\mathrm{C}$ were found with myocardial zinc level and activities of erythrocytes antioxidant enzymes SOD and GPx. Of interest is that the relationship of vitamin $\mathrm{C}$ with other parameters was of an exponential character (Fig. 3A). In contrast, vitamin $\mathrm{E}$ did not correlate with $\mathrm{cTnT}$, total 


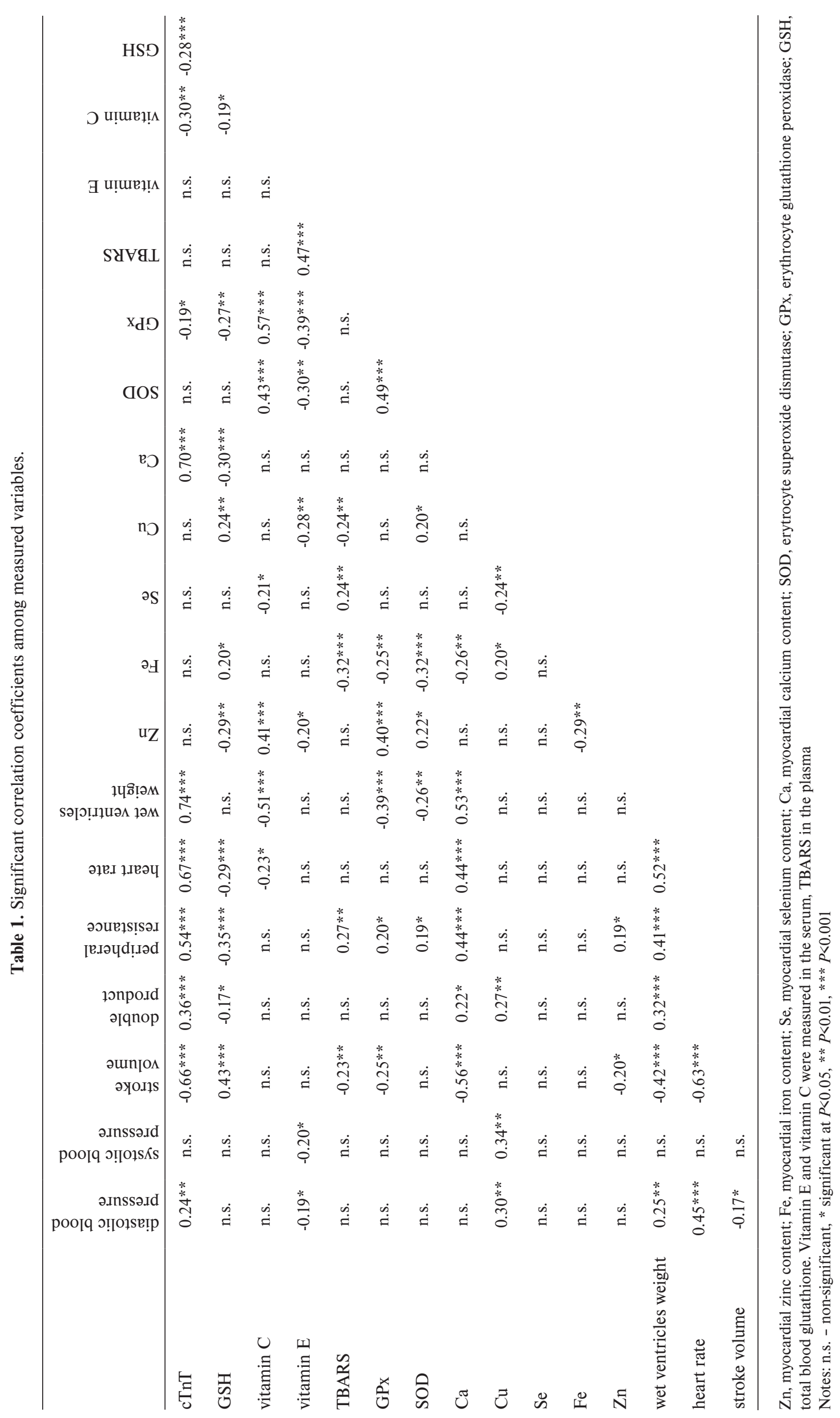


blood glutathione, wet ventricle weight, myocardial calcium content, stroke volume, heart rate or total peripheral resistance at all. However, its negative correlation with the erythrocyte enzymes SOD and GPx activities, and a positive one with TBARS, are of note. Analogously to vitamin E, TBARS did not correlate with other variables or only slightly. For GPx, in addition to the mentioned correlations, a relatively strong correlation was found with myocardial zinc concentration. Myocardial selenium and iron did not correlate with almost any of the variables. Interestingly, there was an intermediately strong correlation of myocardial copper level with diastolic and systolic blood pressures.

In the analysis of relationship among haemodynamic parameters, an interesting correlation was found between heart rate and diastolic blood pressure, but not with systolic blood pressure.

\section{DISCUSSION}

\section{Biomarkers of the cardiovascular injury}

cTnT and cTnI are the most commonly used biomarkers of cardiac injury at the moment. They are used successfully in the diagnosis of AMI with better sensitivity over previously used biomarkers. Various studies have described excellent negative correlations of cTnT concentration with the left ventricular contractility impairment or cardiomyocyte viability and positive one with myocardial infarction size $\mathrm{e}^{15,16}$. In our previous study, we established a correlation of the cTnT concentration with cardiac function parameters in a relatively small number of animals ${ }^{10}$. In the present study, the relation of the cTnT levels with the other haemodynamic variables was further confirmed, extended and mathematically evaluated. The dependence of cTnT concentration on most of measured parameters was of an exponential character, e.g. it could be transformed into a linear relationship in the semilogarithmic plot. Similarly, other authors reported the exponential relationship between cardiomyocyte viability and cTnT level ${ }^{15}$. A more complicated relationship (power function) was found between myocardial calcium content and cTnT level.

One prominent feature of the various cardiovascular diseases is the "calcium overload" ${ }^{17,18}$. Like cTnT, calcium myocardial levels correlated in a similar manner with the parameters of cardiovascular function. Moreover, in accordance with cTnT, these dependences were again of an exponential type. Our results show the extent of calcium overload can be estimated from cTnT concentration, stroke volume index and heart rate. Interestingly, heart rate correlated positively not only with calcium overload and cTnT, but as well with the diastolic blood pressure and negatively with the stroke volume index. Thus, elevated heart rate suggests impaired cardiovascular function. This has been well documented in humans, where increased heart rate is an important predictor of mortality ${ }^{19}$. High blood pressure is another risk factor of cardiovascular disease ${ }^{20}$ and thus some degree of relation to other parameters was expected. The diastolic blood pressure correlated positively with cTnT concentration and wet ventricle weight, but the systolic blood pressure did not correlate with cardiovascular function parameters at all. A limited correlation for systolic blood pressure was with myocardial copper content. Copper may affect the cardiovascular function, e.g. elevated serum copper levels were found in patients with AMI in relation to the severity of the disease ${ }^{21}$. A serum zinc disturbance was shown in AMI (ref. ${ }^{21,22}$ ) and we found an association between myocardial zinc level and the mean blood pressure in our previous study ${ }^{10}$. However, this association was not confirmed in the present study. Generally, myocardial zinc concentration fluctuation was relatively low in this study - $91 \%$ of data were in a narrow range $(0.80-1.20 \mu \mathrm{mol} / \mathrm{L})$. Studies on myocardial selenium levels in AMI are inconsistent $^{23-25}$, but at least within 30 days after AMI, selenium concentration seems to be stable ${ }^{25}$ and, indeed, only few very weak correlations were found in the present study. In contrast, iron homeostasis perturbance accompanies AMI, but the serum iron concentration did not correlate with the biochemical markers of cardiac injury in accordance with our study ${ }^{26,27}$.

The wet ventricle weight index reflects indirectly the pathological changes in the myocardium, which may include infiltration of leucocytes with inflammatory response and fibrosis, as well. In the present study, owing to the relatively shorter time after cardiovascular insult (i.e. $24 \mathrm{~h}$ after isoprenaline administration), the former was rather present ${ }^{10}$. But still, this factor correlated strongly with the cardiovascular injury.

\section{Interrelationship among parameters of oxidative stress and the cardiovascular dys/function}

A very recent review ${ }^{6}$ of oxidative stress biomarkers and prediction of cardiovascular diseases showed equivocal results. The authors suggested that the currently used markers probably do not precisely reflect the oxidative stress status and/or the different methodological approaches used may be the cause of the variable conclusions. They found, e.g. that the relationship between oxidized LDL and the risk of cardiovascular events may be positive or negative in different sub-populations of patients. Other studies in patients suffering from AMI (with/ without reperfusion) or stable/unstable angina pectoris are inconsistent, as well ${ }^{25,28-33}$. The present study findings are in the harmony with this review. The prediction of cardiovascular dysfunction from the parameters of oxidative stress was of very limited significance, although between some antioxidants and the parameters of oxidative stress significant correlations were found. The only partial exception seems to be the level of total blood glutathione, which correlated weakly positively with stroke volume and negatively with heart rate and myocardial calcium content. The level of oxidized or reduced glutathione may correlate more strongly but this was not measured in this series of experiments and remains to be established in our further study. The complexity of the antioxidant system and an unknown relationship to the cardiovascular function could be demonstrated in the case of serum vitamin $\mathrm{C}$ concentration. Vitamin $\mathrm{C}$ levels correlated strongly neg- 
atively with the wet ventricle weight and less importantly with cTnT concentration. However no correlation was found with calcium levels, which, as mentioned above, shows strong correlations with both previously cited parameters. In addition, an obviously contradictory finding is the weak negative correlation of vitamin $\mathrm{C}$ with total blood glutathione. Interestingly, serum vitamin $\mathrm{C}$ concentrations, myocardial zinc levels and erythrocyte antioxidant enzymes SOD and GPx activities mutually correlated positively, but again, no or only very approximate relation to cardiovascular dys/function was detected. Associations of vitamin E levels are even more confounding. The published studies suggested the central role of vitamin $\mathrm{E}$ in the antioxidant system and the necessity to cooperate with other antioxidants, in particular with vitamin $C$. But in the contrast to vitamin $C$, vitamin $E$ did not correlate in this study with any measured parameter of the cardiovascular dysfunction (with the exception of the weak negative correlation with blood pressure). TBARS has been used as an indicator of malondialdehyde, a stable product of lipid peroxidation, and therefore a marker of oxidative stress. However, malondialdehyde is the only one of several substances that react with thiobarbituric acid and malondialdehyde measured by HPLC did not correlate with TBARS (ref. ${ }^{6,30}$ ). Other studies found no correlation of TBARS with the biochemical parameters of cardiac injury or plasma iron, but positive correlation with C-reactive protein was found ${ }^{27,29,32}$. The highly significant positive correlation of vitamin $\mathrm{E}$ with TBARS (Fig. 3C) is therefore of unknown meaning and in contrast another study showed in extreme exercisers, a more specific marker of lipid peroxidation $\mathrm{F}_{2}$-isoprostane correlated negatively with vitamin $\mathrm{E}_{\text {level }}{ }^{24,35}$.

There are two probable explanations for the failure of the markers of oxidative stress to predict the cardiovascular dys/function: 1) the currently used biomarkers do not accurately reflect oxidative stress; 2 ) the oxidative stress status does not correspond to the cardiovascular dys/function. The first reason seems not to be very likely because the cardiovascular diseases in general, as well as the used model of cardiotoxicity, are considered to be associated with oxidative stress ${ }^{5,36-38}$ and even if TBARS may be not an accurate indicator of oxidative stress, vitamins $\mathrm{E}$ and $\mathrm{C}$ or antioxidant enzymes should at least partly react on the oxidative stress status. Therefore, we are of that opinion, that even if oxidative stress is an accompanying factor of the cardiovascular derangement, the commonly used oxidative stress biomarkers cannot be used for the assessment of cardiovascular dysfunction.

\section{ACKNOWLEDGEMENTS}

The experimental work was supported by Charles University (grant No. 39207C and project SVV 263 003) and by the project of the Ministry of Health, Czech Republic for conceptual development of research organization 00179906.

\section{CONFLICT OF INTEREST}

Authors' conflict of interest disclosure: The authors stated that there are no conflicts of interest regarding the publication of this article.

\section{REFERENCES}

1. Dahlof B. Cardiovascular disease risk factors: epidemiology and risk assessment. Am J Cardiol 2010;105(1 Suppl):3A-9A.

2. Goldberg RJ, Glatfelter K, Burbank-Schmidt E, Lessard D, Gore JM. Trends in community mortality due to coronary heart disease. Am Heart J 2006;151(2):501-7.

3. Wilkins JT, Lloyd-Jones DM. Biomarkers for coronary heart disease clinical risk prediction: a critical appraisal. Counterpoint. Prev Cardiol 2010;13(4):160-5.

4. Abegunde DO, Mathers CD, Adam T, Ortegon M, Strong K. The burden and costs of chronic diseases in low-income and middle-income countries. Lancet 2007;370(9603):1929-38.

5. Fearon IM, Faux SP. Oxidative stress and cardiovascular disease: novel tools give (free) radical insight. J Mol Cell Cardiol 2009;47(3):372-81.

6. Strobel NA, Fassett RG, Marsh SA, Coombes JS. Oxidative stress biomarkers as predictors of cardiovascular disease. Int J Cardiol 2011;147(2):191-201.

7. Peng YX, Shan J, Qi XY, Zhang SJ, Ma SP, Wang N, Li JP, Xue H, Wu M. The catecholamine-beta-adrenoreceptor-cAMP system and prediction of cardiovascular events in hypertension. Clin Exp Pharmacol Physiol 2006;33(3):227-31.

8. Rona G. Catecholamine cardiotoxicity. J Mol Cell Cardiol 1985;17(4):291-306.

9. Krenek P, Kmecova J, Kucerova D, Bajuszova Z, Musil P, Gazova A, Ochodnicky P, Klimas J, Kyselovic J. Isoproterenol-induced heart failure in the rat is associated with nitric oxide-dependent functional alterations of cardiac function. Eur J Heart Fail 2009;11(2):140-6.

10. Mladenka P, Hrdina R, Bobrovova Z, Semecky V, Vavrova J, Holeckova M, Palicka V, Mazurova Y, Nachtigal P. Cardiac biomarkers in a model of acute catecholamine cardiotoxicity. Hum Exp Toxicol 2009;28(10):631-40.

11. Mladenka $P$, Kalinowski DS, Haskova $P$, Bobrovova $Z$, Hrdina R, Simunek T, Nachtigal P, Semecky V, Vavrova J, Holeckova M, Palicka V, Mazurova Y, Jansson PJ, Richardson DR. The novel iron chelator, 2-pyridylcarboxaldehyde 2-thiophenecarboxyl hydrazone, reduces catecholamine-mediated myocardial toxicity. Chem Res Toxicol 2009;22(1):208-17.

12. Mladenka P, Semecky V, Bobrovova Z, Nachtigal P, Vavrova J, Holeckova M, Palicka V, Mazurova Y, Hrdina R. The effects of lactoferrin in a rat model of catecholamine cardiotoxicity. Biometals 2009;22(2):353-61.

13. Mladenka P, Zatloukalova $L$, Simunek T, Bobrovova Z, Semecky V, Nachtigal P, Haskova P, Mackova E, Vavrova J, Holeckova M, Palicka V, Hrdina R. Direct administration of rutin does not protect against catecholamine cardiotoxicity. Toxicology 2009;255(1-2):25-32.

14. Zatloukalová L, Filipský $T$, Mladěnka $P$, Semecký V, Macáková $K$, Holečková M, Vávrová J, Palicka V, Hrdina R. Dexrazoxane provided moderate protection in a catecholamine model of severe cardiotoxicity. Can J Physiol Pharmacol 2012;90(4):473-84.

15. Adamcova $M$, Simunek $T$, Kaiserova $H$, Popelova O, Sterba $M$, Potacova A, Vavrova J, Malakova J, GersI V. In vitro and in vivo examination of cardiac troponins as biochemical markers of drug-induced cardiotoxicity. Toxicology 2007;237(1-3):218-28.

16. Gibbons RJ, Valeti US, Araoz PA, Jaffe AS. The quantification of infarct size. J Am Coll Cardiol 2004;44(8):1533-42.

17. Fleckenstein-Grun G, Frey M, Thimm F, Hofgartner W, Fleckenstein A. Calcium overload--an important cellular mechanism in hypertension and arteriosclerosis. Drugs 1992;44 Suppl 1:23-30.

18. Janke J, Fleckenstein A, Doring HJ, Leder O. [Key-role of intracellular calcium overload in acute necrosis of the myocardium. Cardioprotection with verapamil]. Minerva Med 1975;66(38):184658.

19. Feldman D, Elton TS, Menachemi DM, Wexler RK. Heart rate control with adrenergic blockade: clinical outcomes in cardiovascular medicine. Vasc Health Risk Manag 2010;6:387-97. 
20. Lawes CM, Bennett DA, Lewington S, Rodgers A. Blood pressure and coronary heart disease: a review of the evidence. Semin Vasc Med 2002;2(4):355-68.

21. Jain VK, Mohan G. Serum zinc and copper in myocardial infarction with particular reference to prognosis. Biol Trace Elem Res 1991;31(3):317-22.

22. Arnaud J, Faure H, Bourlard P, Denis B, Favier AE. Longitudina changes in serum zinc concentration and distribution after acute myocardial infarction. Clin Chim Acta 1994;230(2):147-56.

23. Bor MV, Cevik C, Uslu I, Guneral F, Duzgun E. Selenium levels and glutathione peroxidase activities in patients with acute myocardial infarction. Acta Cardiol 1999;54(5):271-6.

24. Kok FJ, Hofman A, Witteman JC, de Bruijn AM, Kruyssen DH, de Bruin $M$, Valkenburg HA. Decreased selenium levels in acute myocardial infarction. Jama 1989;261(8):1161-4.

25. Zachara BA, Ukleja-Adamowicz M, Nartowicz E, Lecka J. Increased plasma glutathione peroxidase activity in patients with acute myocardial infarction. Med Sci Monit 2001;7(3):415-20.

26. van der Schouw YT, van der Veeken PM, Kok FJ, Koster JF, Schouten EG, Hofman A. Iron status in the acute phase and six weeks after myocardial infarction. Free Radic Biol Med 1990;8(1):47-53.

27. Cottin Y, Doise JM, Maupoil V, Tanniere-Zeller M, Dalloz F, Maynadie M, Walker MK, Louis P, Carli PM, Wolf JE, Rochette L. Plasma iron status and lipid peroxidation following thrombolytic therapy for acute myocardial infarction. Fundam Clin Pharmacol 1998;12(2):236-41.

28. Dubois-Rande JL, Artigou JY, Darmon JY, Habbal R, Manuel C, Tayarani I, Castaigne A, Grosgogeat Y. Oxidative stress in patients with unstable angina. European Heart Journal 1994;15(2):179-83.

29. Ohlin H, Gustavsson CG, Pantev E, Thorvinger B, Ohlin AK. Transient release of lipid peroxidation products as a non-invasive marker of successful reperfusion after thrombolysis for myocardial infarction. Br Heart J 1995;73(3):223-6.
30. Olsson KA, Harnek J, Ohlin AK, Pavlidis N, Thorvinger B, Ohlin H. No increase of plasma malondialdehyde after primary coronary angioplasty for acute myocardial infarction. Scand Cardiovasc J 2002:36(4):237-40.

31. Dwivedi VK, Chandra M, Misra PC, Misra A, Misra MK. Status of some free radical scavenging enzymes in the blood of myocardial infarction patients. J Enzyme Inhib Med Chem 2006;21(1):43-6.

32. Pucheu S, Coudray C, Vanzetto G, Favier A, Machecourt J, de Leiris J. Assessment of radical activity during the acute phase of myocardial infarction following fibrinolysis: utility of assaying plasma malondialdehyde. Free Radic Biol Med 1995;19(6):873-81.

33. Lafont A, Marwick TH, Chisolm GM, Van Lente F, Vaska KJ, Whitlow PL. Decreased free radical scavengers with reperfusion after coronary angioplasty in patients with acute myocardial infarction. Am Heart J 1996;131(2):219-23.

34. Milne GL, Musiek ES, Morrow JD. F2-isoprostanes as markers of oxidative stress in vivo: an overview. Biomarkers 2005;10 Suppl 1:S1023

35. Traber MG, Atkinson J. Vitamin E, antioxidant and nothing more. Free Radic Biol Med 2007;43(1):4-15.

36. Bindoli A, Rigobello MP, Deeble DJ. Biochemical and toxicologica properties of the oxidation products of catecholamines. Free Radic Biol Med 1992;13(4):391-405.

37. Haskova P, Kovarikova P, Koubkova L, Vavrova A, Mackova E, Simunek T. Iron chelation with salicylaldehyde isonicotinoyl hydrazone protects against catecholamine autoxidation and cardiotoxicity. Free Radic Biol Med 2011;50(4):537-49.

38. Chagoya de Sanchez V, Hernandez-Munoz R, Lopez-Barrera F, Yanez L, Vidrio S, Suarez J, Cota-Garza MD, Aranda-Fraustro A, Cruz D. Sequential changes of energy metabolism and mitochondrial function in myocardial infarction induced by isoproterenol in rats: a long-term and integrative study. Can J Physiol Pharmacol 1997;75(12):1300-11. 